\title{
Review
}

\section{Sphincterotomy and the treatment of detrusor-sphincter dyssynergia: current status, future prospects}

\author{
JM Reynard*,1,2, J Vass ${ }^{2}$, ME Sullivan ${ }^{2}$ and M Mamas ${ }^{3}$ \\ ${ }^{1}$ The National Spinal Injuries Centre, Stoke Mandeville Hospital, UK; ${ }^{2}$ Department of Urology, The Churchill \\ Hospital, Oxford, UK, ${ }^{3}$ Nuffield Department of Medicine, John Radcliffe Hospital, Oxford, UK
}

\begin{abstract}
Study design: Literature review of current treatment options for detrusor-sphincter dyssynergia (DSD) in spinal cord injury.

Objectives: To review the outcomes and complications associated with external sphincterotomy and to summarise the results and complications of alternative treatment options for detrusor-sphincter dyssynergia in spinal cord injury. In addition, we propose a potential alternative future drug treatment for external sphincter dyssynergia based upon recent research on the neuropharmacology of the external urethral sphincter.
\end{abstract}

Setting: The National Spinal Injuries Centre, Stoke Mandeville Hospital, Aylesbury, UK.

Methods: Medline search from 1966 to 2002 using the words 'external sphincterotomy', 'detrusor-sphincter dyssynergia' and 'neurogenic bladder combined with surgery'.

Results: While external sphincterotomy is an effective treatment for DSD, a significant number of men following this procedure continue to have high intrarenal pressures, recurrent urinary infection or troublesome autonomic dysreflexia and a worryingly high proportion demonstrate persistently raised leak point pressures, putting them at subsequent risk of renal damage. Alternative treatments for external sphincter dyssynergia include urethral stents and balloon dilatation, both of which are effective. However, over the long term stents can undergo encrustation and there remains a definite risk of stent migration necessitating stent removal or replacement. Balloon dilatation of the external sphincter is associated with a risk of subsequent stricture formation. Intraurethral Botulinum A toxin seems to be effective though there have been no large randomised studies comparing it against placebo. However, it is not a durable treatment option and it has not found a common place in the treatment of DSD. There is now a considerable amount of experimental data from both animal and human studies to suggest that nitric oxide (NO) is an important physiological inhibitory neurotransmitter in the urethral sphincter, mediating relaxation of the external urethral sphincter. The potential role of sphincter NO augmentation for treatment of DSD is discussed.

Conclusion: External sphincterotomy remains the mainstay of treatment for urodynamically significant detrusor-sphincter dyssynergia, but in recent years a number of effective, alternative treatment options have become available. While at present there is no effective systemic drug treatment, recent research into external sphincter neuropharmacology suggests that systemic or topical augmentation of external sphincter NO may provide an effective method for lowering sphincter pressure.

Spinal Cord (2003) 41, 1-11. doi:10.1038/sj.sc.3101378

Keywords: external sphincterotomy; detrusor-external sphincter dyssynergia; urethral stents; nitric oxide

*Correspondence: JM Reynard, The National Spinal Injuries Centre, Stoke Mandeville Hospital, Aylesbury, Buckinghamshire HP21 8AL, UK

\section{Introduction}

'Neurourologists have not yet found the ideal treatment for urodynamically significant detrusor-sphincter dyssynergia in male patients'. ${ }^{1}$ Many patients with spinal cord injuries lose the reciprocal relationship between bladder and urethral sphincter function, such that when 
the detrusor muscle contracts during attempted bladder emptying, the external urethral sphincter also contracts. This is so-called detrusor-external sphincter dyssynergia or DSD. It is a common cause of bladder outlet obstruction in spinal cord injured men, and results in high intravesical pressures, poor bladder emptying associated with recurrent febrile urinary tract infections, autonomic dysreflexia, vesicorenal reflux and hydronephrosis, the latter reflecting high intrarenal pressures. Untreated, progressive renal damage may occur. Indeed, inability to adequately prevent progressive deterioration in renal function was the main reason why, historically, renal failure was the leading cause of death in spinal cord injured patients, a situation which has only recently changed, with urological causes of death having slipped to fourth place. ${ }^{2}$

External sphincterotomy is the mainstay of treatment for DSD. Sphincterotomy is designed to overcome the functional obstruction of DSD thereby improving bladder emptying and converting high pressure incontinence to low pressure incontinence and in so doing protecting the upper tracts. A degree of continence may be maintained if bladder neck function is preserved. Improved bladder emptying reduces the frequency of febrile urinary tract infections (UTIs), and reduces end-fill bladder and voiding bladder pressures, leading to resolution of hydronephrosis and vesicoureteric reflux, so preventing pressure-induced renal damage. More efficient bladder emptying may also reduce the severity or result in complete resolution of autonomic dysreflexia.

While external sphincterotomy results in a successful outcome in many patients, a significant proportion continue to have problems as a consequence of persistent hydronephrosis, vesicoureteric reflux, febrile urinary tract infections or autonomic dysreflexia. A substantial number of patients will have persistently raised leak point pressures after external sphincterotomy, exposing them to subsequent risk of renal damage.

The number of recent publications describing the complications and failure rate of external sphincterotomy (ES) combined with reports of alternative treatments for detrusor - external sphincter dyssynergia (DSD) support Alan Wein's sentiments that 'Neurourologists have not yet found the ideal treatment for urodynamically significant detrusor-sphincter dyssynergia in male patients'. ${ }^{1}$ In this review, the history of sphincterotomy, the current technique of performing this procedure and its results are discussed, together with alternative methods for managing DSD. A potential future drug treatment is also proposed.

\section{Methods}

A Medline search from 1966 to 2002 was conducted using the words 'external sphincterotomy', 'detrusorsphincter dyssynergia' and 'neurogenic bladder combined with surgery'. A total of 676 records were obtained ('external sphincterotomy', 98; 'detrusorsphincter dyssynergia,' 66; 'neurogenic bladder/surgery', 512).

To identify recent papers manual searches were also conducted of the last 2 years of the British Journal of Urology International, The Journal of Urology, Urology, European Urology, The Scandinavian Journal of Urology and Nephrology, Spinal Cord, The Journal of Spinal Cord Medicine, Archives of Physical Medicine and Rehabilitation and The Journal of the American Paraplegia Society. Abstracts from leading urological and spinal cord medicine congresses (The AUA, SIU, BAUS, EAU and IMSOP) were also identified.

\section{History of sphincterotomy}

In the 1940s and early 1950s Emmett $^{3,4}$ and others ${ }^{5}$ carried out transurethral bladder neck resections in patients with spinal cord injuries and bladder outlet obstruction (BOO). While the obstruction was relieved in some cases, in most the results were disappointing - the obstruction persisted. Some years earlier, Watkins had suggested that the increased urethral resistance in spinal cord injured males lay distally in the urethra, at the level of the urogenital diaphragm. ${ }^{6}$ Donovan had shown that dilatation of the urethra resulted in temporary resolution of $\mathrm{BOO}^{7}$ and suggested that 'the proper course may be to remove permanently the obstruction ... in the region of the triangular ligament'.

In 1956 Ross et al reported the results of 10 cases in which the external sphincter was deliberately divided in spinal cord injured patients with bladder outlet obstruction. The cold punch was used to resect three to five strips of tissue posterolaterally at the level of the external sphincter. No electrocoagulation was used (it was deemed ineffectual) and a large bore catheter ( 22 to $26 \mathrm{Ch}$ ) was inserted to tamponade the subsequent haemorrhage. Blood transfusions were given routinely. One patient died from bleeding and one from uraemia. The technique of external sphincterotomy has been refined over the years, and sphincterotomy is now the mainstay of treatment for DSD.

\section{Current technique}

Using a Colling's electrocautery knife an anterior (11, 12 or 1 o'clock) incision is made beginning at the level of the proximal part of the verumontanum and ending in the corpus spongiosum of the bulbar urethra. The depth of incision can be difficult to gauge. Some recommend the incision should continue until the plane of the periurethral venous sinuses is reached. ${ }^{9}$ This plane becomes self-evident when heavy bleeding is encountered. A $22 \mathrm{Ch}$ urethral catheter is left in position for $24-48 \mathrm{~h}$ to tamponade the bleeding, and to allow continuous bladder irrigation so preventing clot retention, and thus allowing adequate bladder drainage. 


\section{Indications for external sphincterotomy}

The current indications for external sphincterotomy include: DSD causing (a) hydronephrosis; (b) vesicoureteric reflux (VUR); (c) autonomic dysreflexia (due to poor bladder emptying); (d) recurrent UTIs (due to poor bladder emptying).

\section{Results of external sphincterotomy}

Anteromedian external sphincterotomy has become the established technique for sphincterotomy, because it is thought to reduce the risk of severe haemorrhage and of erectile dysfunction. The results presented here are those for anteromedian sphincterotomy (either at the 11,12 or 1 o'clock position), unless otherwise stated. A successful sphincterotomy may be variously defined as one that results in:

(a) resolution of hydronephrosis

(b) reduction in frequency of or complete resolution of UTIs

(c) reduction in frequency of or resolution of autonomic dysreflexia

(d) reduction in post-void residual urine volume

(e) reduction in voiding pressure

(f) improvement in the radiological 'appearance' of the sphincter

(g) reduction in leak point pressure

Results of anteromedian external sphincterotomy: resolution of hydronephrosis or VUR

The majority of patients in published studies do not have hydronephrosis or VUR prior to external sphincterotomy. Of those who do, Catz et al ${ }^{10}$ reported resolution of hydronephrosis in two out of three cases (total study population $=32$ ) and Fontaine et $a l^{11}$ noted resolution in all three patients (study population $=92$ ). VUR resolved in nine out of 10 patients in Fontaine's series. In Carrion's report of 60 subjects, in those six patients with bilateral reflux (12 affected renal 'units'), complete resolution was noted in nine renal units and out of the eight patients with unilateral reflux six were cured and two improved from grade III to grade I. ${ }^{12}$ Overall $75 \%$ of patients were cured of their reflux. Catz et al noted that the reflux disappeared in two out of five patients, and in the other three cases bilateral reflux became unilateral and in one of these three the grade of reflux improved from grade III to grade I. $^{10}$

\section{Results of anteromedian external sphincterotomy: reduction in frequency of or resolution of UTIs}

In Catz's series recurrent 'clinical infections' ('clinical infection' was not defined) disappeared in 14 out of 19 men $(74 \%)$ who had infection pre-operatively and in another four patients asymptomatic bacteruria disappeared. ${ }^{10}$ Fontaine et $a l^{11}$ reported resolution of febrile UTIs in 33 out of 43 patients $(77 \%)$.

\section{Results of anteromedian external sphincterotomy: reduction or resolution of autonomic dysreflexia}

Patients with autonomic dysreflexia respond well to external sphincterotomy with Fontaine et $a l^{11}$ reporting resolution in 41 out of 44 cases $(93 \%)$, Catz et $a l^{10}$ in two out of two cases $(100 \%)$ and Ricottone et $a l^{13}$ in 10 out of 11 cases $(91 \%)$.

Results of anteromedian external sphincterotomy: reduction in post-void residual urine volume (PVR)

Fontaine et $a l^{11}$ noted that mean residual urine volume fell from $210 \mathrm{ml}$ pre-operatively to $100 \mathrm{ml}$ following sphincterotomy. In Carrion's ${ }^{12}$ series pre-operative residual urine volume was between $51-100 \mathrm{ml}$ in six, $101-200 \mathrm{ml}$ in 21 and between $201-300 \mathrm{ml}$ in 33 . Immediately post-operatively residual urine volume was $<50 \mathrm{ml}$ in $52,51-100 \mathrm{ml}$ in three and $101-$ $200 \mathrm{ml}$ in five. However, of those who had been followed up at 12 months post-operatively, 24 had a PVR $<50 \mathrm{ml}$, one had a PVR between $51-100 \mathrm{ml}$ and seven had a PVR of between $101-200 \mathrm{ml}^{12}$ In Catz's series pre-operative PVR was $>100 \mathrm{ml}$ in all 32 patients, $100-200 \mathrm{ml}$ in $34 \%$ and $>200 \mathrm{ml}$ in $66 \%$. PVR decreased to $<100 \mathrm{ml}$ in $69 \%$, to between 100 and $200 \mathrm{ml}$ in $19 \%$ and remained $>200 \mathrm{ml}$ in just $12 \%{ }^{10}$ In Santiago's ${ }^{14}$ report $(n=25)$ residual urine volume fell from a mean of 350 to $<50 \mathrm{ml}$ in all cases.

Results of anteromedian external sphincterotomy: reduction in mean voiding pressure

Fontaine et $a l^{11}$ reported a reduction in mean detrusor voiding pressure from 82 to $41 \mathrm{~cm} \mathrm{H}_{2} \mathrm{O}$ following external sphincterotomy. At 12 months post-sphincterotomy Chancellor et $a l^{15}$ found that average maximum detrusor pressure had decreased from 98 to $49 \mathrm{~cm}$ $\mathrm{H}_{2} \mathrm{O}$.

\section{Results of anteromedian external sphincterotomy: radiological definition of success}

Fontaine et $a l^{11}$ established that the value for the ratio of supra-sphincteric urethral diameter to infra-sphincteric urethral diameter in 20 normal males aged $<40$ was one or less. In men with DSD this ratio is greater than one. Fontaine et $a l^{11}$ used a decrease in this ratio as an indication of a successful sphincterotomy. In 92 cases of sphincterotomy mean supra-sphincteroprostatic: infra-sphincteric urethral ratio decreased from 2.95 to 1.33 .

Results of anteromedian external sphincterotomy: reduction in Leak Point Pressure (LPP)

LPP is the bladder pressure at which urine flow starts. McGuire et $a l^{16}$ has shown that patients with neuropathic bladders and LPPs $>40 \mathrm{~cm} \mathrm{H}_{2} \mathrm{O}$ have an increased risk of subsequent renal damage. Follow- 
ing sphincterotomy in spinal cord injured men, Kim et $a l^{17}$ found that 19 out of $55(35 \%)$ patients had a reduction in LPP to $<40 \mathrm{~cm} \mathrm{H}_{2} \mathrm{O}$ and 36 out of 55 $(65 \%)$ had a leak point pressure $>40 \mathrm{~cm} \mathrm{H}_{2} \mathrm{O}$. Twenty-four of the 36 patients $(67 \%)$ with a LPP of $>40 \mathrm{~cm} \mathrm{H}_{2} \mathrm{O}$ had persistent DSD, compared with 3 out of $19(16 \%)$ with a LPP $<40 \mathrm{~cm} \mathrm{H}_{2} \mathrm{O}$. Ten out of $36(28 \%)$ with a LPP $>40 \mathrm{~cm} \mathrm{H}_{2} \mathrm{O}$ had evidence of renal damage (subsequent development of pyelonephritis, hydronephrosis or renal scars) compared with one out of $19(5 \%)$ with a LPP $<40 \mathrm{~cm} \quad \mathrm{H}_{2} \mathrm{O}$ patients. ${ }^{17}$ Thus, a LPP $>40 \mathrm{~cm} \mathrm{H}_{2} \mathrm{O}$ post-external sphincterotomy is associated with a significantly higher incidence of upper tract damage and persistent DSD when compared with a LPP $<40 \mathrm{~cm} \mathrm{H}_{2} \mathrm{O}$.

\section{Alternative techniques of sphincterotomy}

External sphincterotomy can be performed with a laser and this is thought to decrease intra-operative and peri-operative haemorrhage with no additional morbidity, though there have been no randomised trials comparing laser sphincterotomy with conventional sphincterotomy.

Perkash et $a l^{18}$ performed 12 o'clock laser sphincterotomy with a sapphire tip contact $\mathrm{Nd}$ : YAG laser in 40 spinal cord injured men, 37 (93\%) of whom had DSD. Fifty per cent had had previous transurethral surgery and $32 \%$ had concomitant bulbar urethral strictures. Blood loss was estimated to be between 25 to $50 \mathrm{ml}$ per patient except for two cases where the estimated loss of blood was $100-150 \mathrm{ml}$. Mean follow-up was 9 months, when all were reported to be voiding well. ${ }^{18}$

Rivas et $a l^{19}$ used a neodymium:YAG laser for external sphincterotomy in 22 spinal cord injured men with DSD (and three men with concurrent bladder neck obstruction). Mean duration of surgery was 45 min and mean hospitalisation was 2.7 days. No blood transfusions were required. At 12 months of follow-up mean voiding pressure had fallen from 87 to $47 \mathrm{~cm} \mathrm{H}_{2} \mathrm{O}$ and residual urine volume from 122 to $33 \mathrm{ml}$. Recurrent sphincter obstruction at 12 months occurred in three $(14 \%)$. One patient had diminished erectile function post-operatively. ${ }^{19}$ Thus, laser sphincterotomy may reduce the need for blood transfusion compared with conventional sphincterotomy, though clearly without a randomised trial comparing the two techniques, it is difficult to be certain about this.

\section{Definition of failure of external sphincterotomy}

Persistence of hydronephrosis or VUR, continued recurrent urinary infection or autonomic dysreflexia clearly represent a failure of external sphincterotomy.

The reasons for failure may be: (a) inadequate sphincterotomy (persistent DSD suggests this is the case); (b) detrusor hypocontractility resulting in inefficient bladder emptying and so persistent UTIs; (c) urethral stricture.
Persistent obstruction may be due to bladder neck obstruction which only becomes apparent after treatment of the DSD. Although this does not per se represent a failure of external sphincterotomy, nonetheless it is a cause of persistent bladder outlet obstruction.

Management of failed sphincterotomy consists of either repeat sphincterotomy or catheter drainage (intermittent or indwelling). Persistent obstruction due to bladder neck obstruction can be managed by a trial of alpha adrenergic blocking drugs or by bladder neck incision or resection.

\section{Predicting failure of external sphincterotomy}

Light et $a l^{20}$ studied urodynamic and neurophysiologic factors which could be used to predict failure of sphincterotomy with a view to avoiding an operation which is unlikely to work. All nine patients studied, all of whom had lesions above T4 and who had failed sphincterotomy (defined as persistent or increased residual urine volumes) had an abnormality of either the sensory or motor limb of the somatic sacral reflex arc ie. a lesion far distant from their site of injury as identified by lumbosacral evoked potentials to tibial nerve stimulation (absent $\mathrm{R}$ or root waves or absent $\mathrm{S}$ or spinal interneuron waves). Effectively these patients with upper motor neuron neurological lesions had lower motor neuron type bladders. In addition, Light et al found that the rate of rise of detrusor pressure to $\mathrm{P}_{\text {iso }}$ (maximum isometric pressure, ie maximum pressure before voiding) was prolonged in seven out of nine patients and the rise in pressure occurred in a stepladder fashion. $^{20}$ This was interpreted as indicating further evidence of reduced sensory input to the bladder (sensory input arising from bladder filling is necessary to initiate a detrusor contraction). In addition to this finding, intravesical pressure in these patients decreased to levels of hypocontractility, so that the detrusor was incapable of providing sufficient force to empty the bladder even despite the lowered sphincter resistance. Light et $a l^{20}$ suggested that sphincterotomy is contraindicated with a combination of slow rise time and abnormal lumbosacral evoked potentials or low $\mathrm{P}_{\text {iso }}$ or detrusor contraction of short duration.

Lockhart et $a l^{21}$ reported that failure of sphincterotomy - defined as persistent symptomatic UTIs or persistent high residual urine volumes above $100 \mathrm{ml}-$ was more likely in those with detrusor areflexia than in those with hyperreflexia. Forty-five out of 60 sphincterotomies $(75 \%)$ were successful and $15(25 \%)$ were failures. Thirty-seven ( $82 \%)$ of the 'successful' sphincterotomies had detrusor hyperreflexia and eight $(18 \%)$ had areflexia. Ten out of the 15 'failures' $(66 \%)$ had detrusor areflexia and five $(33 \%)$ had detrusor hyperreflexia. About $50 \%$ of the areflexic group exhibited high post-void residual urine volume (above $100 \mathrm{ml}$ ) post-operatively. Out of the 18 areflexic men, eight $(45 \%)$ had a successful outcome (i.e. residual urine volume fell or recurrent UTIs resolved) and 10 
$(55 \%)$ did not. ${ }^{21}$ So, many areflexic men (about half) will do well after sphincterotomy, in terms of reduction in residual urine volume or resolution of UTIs, though many (about half) will not. Out of the men with detrusor hyperreflexia $(n=42), 84 \%$ had a successful sphincterotomy and $16 \%$ did not. ${ }^{21}$

Nanninga et $a l^{22}$ thought that persistence of residual urine after sphincterotomy may be due to loss of Barrington's urethrovesical reflex, whereby stimulation of the posterior urethra by the passage of urine sustains the detrusor contraction. Seven patients with residual urine volumes above $80 \mathrm{ml}$ after sphincterotomy underwent urodynamic evaluation and all demonstrated poorly sustained detrusor contractions. All seven patients demonstrated a sustained detrusor pressure during voiding pre-operatively. Nanninga et $a l^{22}$ did not determine whether poorly sustained detrusor contractions identified pre-operatively could be used to predict the presence of elevated residual urine volumes post-operatively.

Yang and $\mathrm{Mayo}^{23}$ found that age, level of injury, previous bladder neck or sphincter operation and preoperative PdetMax were unable to predict failure of sphincterotomy.

\section{Long-term risk of upper tract deterioration post-sphincterotomy}

Juma et $a l^{24}$ followed 63 patients for a mean of 11 years (range 2-30 years) after sphincterotomy. Nineteen $(30 \%)$ had upper tract complications - renal calculi in 12, atrophic kidneys in one, VUR in five, and renal scarring with impaired renal function in 11 . Half of these complications developed $>2$ years after sphincterotomy. LPP was able to predict risk of upper tract complications which was $<25 \%$ when LPP was $<40 \mathrm{~cm} \mathrm{H}_{2} \mathrm{O}$ and $50 \%$ when LPP was $>70 \mathrm{~cm} \mathrm{H}_{2} \mathrm{O}$ (overall risk of upper tract deterioration for the whole group was $30 \%$ ). Not surprisingly upper tract complications were also more likely in the presence of bacteriuria $(38 \%)$ than in its absence $(13 \%){ }^{24}$

As previously noted Kim et $a l^{17}$ had reported that $28 \%$ of men with a LPP $>40 \mathrm{~cm} \mathrm{H}_{2} \mathrm{O}$ after sphincterotomy had evidence of renal damage (subsequent development of pyelonephritis, hydronephrosis or renal scars) compared with one out of $19(5 \%)$ with a LPP $<40 \mathrm{~cm} \mathrm{H}_{2} \mathrm{O}^{17}$

\section{Complications}

Haemorrhage

Yalla et $a l^{25}$ reported the results of 53 patients undergoing bilateral incisions at 3 and 9 o'clock, compared with 31 who underwent 12 o'clock incision. This was not a randomised study. Eight per cent of the patients undergoing 3/9 o'clock sphincterotomy had postoperative haemorrhage requiring blood transfusion. None of those who underwent 12 o'clock sphincterotomy required transfusion. Kiviat ${ }^{26}$ reported delayed post-operative bleeding requiring admission to hospital for catheterisation and/or transfusion in four out of 17 sphincterotomies $(23 \%)$ at the 3 and 9 o'clock position, compared with one out of 14 (7\%) who had sphincterotomy at the 1 and 11 o'clock position. In Carrion's ${ }^{12}$ series of 12 o'clock sphincterotomy three patients out of 60 required blood transfusion. Vapnek et $a l^{27}$ stated that blood loss was always $<100 \mathrm{ml}$ and no patient required transfusion. Blood transfusion was required in two out of 15 patients $(13 \%)$ in Chancellor's series. $^{28}$

\section{Erectile dysfunction}

Schoenfeld $e t a l^{29}$ reported a $32 \%$ incidence of postoperative impotence after transurethral resection of the sphincter at the 3 and 9 o'clock positions. Reports followed documenting an incidence of impotence of between 2 to $56 \%{ }^{26,30-33}$ Those reporting rates at the lower end of this range concluded that 3 and 9 o'clock sphincterotomy had no effect on erectile capacity, while those reporting higher rates concluded that sphincterotomy could cause impotence. Kiviat ${ }^{26}$ switched from bilateral three and nine incisions to bilateral 1 and 11 o'clock incisions half way through his series. The study was therefore not randomised. Out of those undergoing 3 and 9 o'clock sphincterotomy five out of 15 patients $(33 \%)$ who had erections pre-operatively lost their erections and six out of $15(40 \%)$ demonstrated partial or temporary loss of erections. One patient out of 14 (7\%) with erections prior to sphincterotomy at the 1 and 11 o'clock position lost his erections. ${ }^{26}$

The adoption of the 12 o'clock sphincterotomy may have resulted in a reduction in the incidence of impotence, though there has been no randomised comparison of 12 o'clock sphincterotomy against 3 and 9 o'clock incision. Loss of erections is still reported with the 12 o'clock position, Carrion et al documenting erectile dysfunction in $3 \%$ of $60 \mathrm{men}^{12}$ and Chancellor et $a l^{28}$ reporting permanent loss of erections in $7 \%$ of cases.

\section{Bladder neck stenosis or stricture}

Bladder neck stenosis or stricture at the site of sphincterotomy or elsewhere in the urethra is reported in between $3-13 \%$ of patients post-sphincterotomy in contemporary series $^{23,24,28}$ (stricture-3\%, bladder neck stenosis $-8 \%$ ).

\section{Re-operation rate}

Fifteen to $40 \%$ of patients subsequently require repeat sphincterotomy. ${ }^{13,14,23,26,27}$

\section{Alternative methods for managing DESD}

Dorsal rhizotomy and sacral anterior root stimulation Dorsal rhizotomy results in resolution of DSD and 
increases bladder compliance and capacity. It is usually combined with simultaneous insertion of the sacral anterior root stimulator to 'drive' micturition. It is a more major undertaking that external sphincterotomy, but many patients experience resolution of recurrent UTIs, autonomic dysreflexia, hydronephrosis and VUR. ${ }^{34}$ The 'ideal' patient for this procedure is the paraplegic female with a hyperreflexic bladder, but it is also a suitable procedure for the male paraplegic and has been used with success in a limited number of tetraplegic patients. Clearly there may be loss of reflex erections, but stimulation of the appropriate anterior roots can overcome this problem.

Alpha blockers Gibbon ${ }^{35}$ stated that 'there are prospects of relief from the use of alpha-adrenergic blocking drugs'. The rationale for the use of alpha blockers was the belief that 'muscle contraction under sympathetic control is probably responsible' for the obstruction in DSD. In a study of 15 patients with DSD and no bladder neck obstruction nor prostatic obstruction, Chancellor et $a l^{36}$ reported the effects of $5 \mathrm{mg}$ of terazosin. Voiding pressures before treatment averaged $92 \mathrm{~cm} \mathrm{H}_{2} \mathrm{O}$, and while on treatment $88 \mathrm{~cm}$ $\mathrm{H}_{2} \mathrm{O}$. After subsequent external sphincterotomy or placement of a urethral stent voiding pressures fell to $38 \mathrm{~cm} \mathrm{H}_{2} \mathrm{O} .{ }^{36}$ Chancellor et $a l^{36}$ concluded that 'our data show that alpha-1 sympathetic blockade has no effect on external sphincter function and does not significantly relieve functional obstruction caused by DESD'. However, it is useful for patients with persistent voiding problems after external sphincterotomy who have bladder neck obstruction. In Chancellor's series five patients who had undergone external sphincterotomy had videocystourethrographic evidence of bladder neck obstruction. While taking terazosin all five improved, both in terms of ease of voiding and also urodynamically, with voiding pressures falling from $80 \mathrm{~cm} \mathrm{H}_{2} \mathrm{O}$ to $51 \mathrm{~cm} \mathrm{H}_{2} \mathrm{O} .{ }^{36}$

Perkash's ${ }^{37}$ findings were similar to those of Chancellor. Twenty-eight men, 11 with 'clear' DSD and 17 with 'minimal to almost absent' DSD received increasing doses of terazosin to a maximum dose of $5 \mathrm{mg}$ daily. Twenty-four underwent urodynamic studies pre- and post-treatment. The mean value for maximum voiding pressure fell by $35 \mathrm{~cm} \mathrm{H}_{2} \mathrm{O}$ in 10 $(42 \%)$, remained the same in nine $(37 \%)$ and increased in five $(21 \%)$. Terazosin was discontinued in three because of side-effects. ${ }^{37}$

Alpha blockers have failed to find a place in the treatment of DSD.

Botulinum A toxin Botulinum A toxin is a protein neurotoxin produced by a bacterium of the Clostridium genus and is an inhibitor of acetylcholine release at the neuromuscular junction. Botulinum toxin injections have previously been used successfully to relieve muscle spasm in facial dystonia and limb spasticity.

Dykstra $e t a l^{38}$ injected botulinum A toxin into the external sphincters of five spinal cord injured men with
DSD once a week for 3 weeks. Urethral pressure profiles decreased on average by $24 \mathrm{~cm} \mathrm{H}_{2} \mathrm{O}$ (from a mean of $78 \mathrm{~cm} \mathrm{H}_{2} \mathrm{O}$ to $54 \mathrm{~cm} \mathrm{H}_{2} \mathrm{O}$ ), residual urine volume decreased by an average of $125 \mathrm{ml}$ (from a mean of 210 to a mean of $85 \mathrm{ml}$ ). Voiding bladder pressures fell from 81 to $53 \mathrm{~cm} \mathrm{H}_{2} \mathrm{O}$. The duration of effect was about 2 months. The main side-effect was mild generalised weakness lasting to 2 to 3 weeks. ${ }^{38}$

Schurch et $a l^{39}$ also evaluated the effects of botulinum-A toxin treatment on DSD in a prospective study on 24 spinal cord injury patients. In this study, 11 paraplegics and 13 tetraplegics $14-63$ years old (mean age 32.2 years) were treated. Different injection protocols were used. Botulinum toxin was injected transurethrally and reinjected $1-3$ months later or was injected monthly for 3 months and then reinjected at 6 and 12 months. In 21 out of the 24 patients, a significant reduction of $48 \%$ in maximum urethral pressure was observed and baseline urethral pressure decreased by $20 \%$. A comparison between the individual protocols was not made. Nine out of 24 patients had a mean decrease in post-void residual volume of $130 \mathrm{ml}$, although in eight patients the post void residual volumes remained high. In the remaining seven patients, in which the post void residual volume was less than $50 \mathrm{ml}$ before treatment, after treatment it remained unchanged. ${ }^{39}$ Interestingly, in the subset of patients who had autonomic dysreflexia, no improvement in their condition was reported following treatment. No side effects of the treatment were reported.

Petit et $a l^{40}$ demonstrated significant reductions in residual volumes, detrusor voiding pressures and urethral pressures in 17 patients with SCI and DSD following botulinum A toxin injection. Phelan et $a l^{41}$ reported their results of cystoscopic injection of botulinum A into the external sphincter in a prospective study. Twenty-one patients were assessed, 12 with DSD, eight with pelvic floor spasticity and one with an acontractile bladder. Nineteen patients had some form of catheterization pre injection whilst only one required catheterization post-injection. Urine residuals decreased by $71 \%$ and voiding pressures by $38 \%{ }^{41}$ Two other very small series have also reported improved bladder function in patients with voiding dysfunction post SCI following sphincteric botulinum A injection. ${ }^{42,43}$

These small studies suggest that botulinim A toxin may be an effective treatment for DSD in some patients, but there have been no large randomised studies comparing it against placebo, and it has not found common use for the treatment of DSD.

\section{Balloon dilatation and Stents}

There have been several well designed studies comparing the effectiveness and complications of balloon dilatation, urethral stents and conventional external sphincterotomy in the treatment of DSD.

Chancellor $e t a l^{28}$ compared balloon dilatation of the sphincter using the OptiLume Prostate Dilator 
under fluoroscopic control to $3 \mathrm{~atm}$ pressure against 12 o'clock sphincterotomy and the Urolume endouretheral Wallstent. This was not a randomised study, since each patient selected his own treatment. In addition the three groups were not strictly comparable, since $40 \%$ of those who elected to undergo sphincterotomy had undergone prior sphincterotomy, while only $27 \%$ and $15 \%$ of those who elected to undergo stent placement or balloon dilatation respectively had had a prior sphincterotomy. ${ }^{28}$ In theory, failure to respond to a previous sphincterotomy might reduce the chance of subsequent successful sphincterotomy, thus introducing bias into the study and potentially making the results of balloon dilatation and stenting seemingly more favourable. Allowing for this, the results suggested that both balloon dilatation and stenting were comparable with sphincterotomy (see Tables 1-3). Follow-up was 12 months for most patients. Mean length of surgery was $44 \mathrm{~min}$ for balloon dilatation, $28 \mathrm{~min}$ for stenting and $62 \mathrm{~min}$ for sphincterotomy. Mean hospitalisation in days was 2.5 for balloon dilatation, 1.3 days for stenting and 3.8 for sphincterotomy. ${ }^{28}$

There was no difference between groups in the percentage of patients experiencing a reduction in the frequency of autonomic dysreflexia.

In terms of complications there were no differences between groups in terms of quality or frequency of erections. In one patient $(7 \%)$ undergoing sphincterotomy there was permanent loss of erections. In terms of haemorrhage the average reduction in $\mathrm{Hb}(\mathrm{g} \%)$ was

Table 1 Numbers and percentages with febrile UTIs requiring hospitalisation 12 months post-surgery (pre-surgery 35 out of 61 patients $(75 \%)$ had UTIs) ${ }^{28}$

\begin{tabular}{lcc}
\hline $\begin{array}{l}\text { Balloon } \\
\text { dilatation }\end{array}$ & Wallstent & $\begin{array}{c}\text { External } \\
\text { sphincterotomy }\end{array}$ \\
\hline $3 / 20(15 \%)$ & $4 / 26(15 \%)$ & $3 / 15(20 \%)$ \\
\hline
\end{tabular}

Table 2 Resolution of hydronephrosis ${ }^{28}$

\begin{tabular}{lcc}
\hline $\begin{array}{l}\text { Balloon } \\
\text { dilatation }\end{array}$ & Wallstent & $\begin{array}{c}\text { External } \\
\text { sphincterotomy }\end{array}$ \\
\hline $2 / 2$ & $4 / 5$ & $1 / 2$ \\
\hline
\end{tabular}

1.4 for balloon dilatation, 1.1 for the UroLume Wallstents and 2.3 for sphincterotomy. Requirement for blood transfusion was $5 \%$ for balloon dilatation, $0 \%$ for UroLume stenting and $13 \%$ for sphincterotomy. One $(5 \%)$ bulbar urethral stricture developed in the balloon dilatation group and two in the sphincterotomy group (13\%). Recurrent obstruction at the level of the external sphincter occurred in $15 \%$ undergoing balloon dilatation at 3,8 and 12 months post-dilatation. No repeat sphincterotomies were required at up to 12 months of follow-up. Stent migration occurred in three out of 26 cases $(12 \%)$, one stent requiring removal, with subsequent successful replacement and the other two cases of migration being managed by placement of a second overlapping stent. No encrustation was reported at 12 months of follow-up.

Chancellor et $a l^{15}$ later reported a prospective, randomised, multicentre trial of the UroLume Wallstent versus external sphincterotomy for DSD in 57 men with urodynamically confirmed DSD. ${ }^{15}$ At 12 months mean maximum detrusor pressure had decreased from $98 \mathrm{~cm} \mathrm{H} \mathrm{H}_{2} \mathrm{O}$ to 49 in the external sphincterotomy group $(n=26)$, and from 96 to $53 \mathrm{~cm}$ $\mathrm{H}_{2} \mathrm{O}$ in the Wallstent group $(n=31 ; P=0.7)$. Mean residual urine volume had fallen from 200 to $98 \mathrm{ml}$ in the external sphincterotomy group and from 191 to $184 \mathrm{ml}$ in the Wallstent group. Hydronephrosis was present in five out of $52(10 \%)$ renal units in the external sphincterotomy patients pre-operatively and in nine out of $69(15 \%)$ renal units in those who subsequently underwent Wallstenting. At 12 months post-treatment hydronephrosis was present in four renal units in the external sphincterotomy group and in none of the Wallstent patients. Eighty-nine per cent in the external sphincterotomy group were hospitalised for 2 or more days, and $63 \%$ of the Wallstent group were hospitalised for 2 or more days. There was a minimal change in haemoglobin in both the sphincterotomy and stent groups $(-1 \mathrm{~g} / \mathrm{dl})$, with no difference between the two. Autonomic dysreflexia improved in nine out of $16(56 \%)$ patients in the external sphincterotomy group and in 13 out of 18 men $(72 \%)$ after Wallstent insertion. Six stents had to be removed, three for migration, one because of initial incorrect placement, one for pain and dysreflexia during voiding and one at the patient's request. Stent removal was accomplished easily in all cases and without subsequent complication. ${ }^{15}$ Thus, the Uro-

Table 3 Post-void residual urine volume and maximum voiding pressure ${ }^{28}$

\begin{tabular}{lrrr}
\hline & $\begin{array}{c}\text { Balloon } \\
\text { dilatation }\end{array}$ & Wallstent & $\begin{array}{l}\text { External } \\
\text { sphincterotomy }\end{array}$ \\
\hline Pre-treatment residual volume $(\mathrm{ml})$ & 163 & 122 & 158 \\
Residual volume $(\mathrm{ml}) 12$ months post-treatment & 67 & 33 & 60 \\
Maximum voiding pressure pre-treatment $\left(\mathrm{cm} \mathrm{H}_{2} \mathrm{O}\right)$ & 83 & 87 & 81 \\
Maximum voiding pressure 12 months post-treatment $\left(\mathrm{cm} \mathrm{H}_{2} \mathrm{O}\right)$ & 36 & 27 & 31 \\
\hline
\end{tabular}


Lume stent certainly seems to compare favourably with the external sphincterotomy group, and if need be it can be easily removed.

In an update of this study of 160 patients who had undergone UroLume stent placement, 21 devices were removed at the time of placement (for misplacement or migration), but all but two were immediately replaced. ${ }^{44}$ Out of the remaining 158 patients who were subsequently followed up, 31 stents required removal. Thus, out of 160 patients $33(20 \%)$ had the stent either immediately removed (two) or removed at a later date (31). Time from implantation to removal ranged from 4 days to 66 months (mean 22 months). Most had no or only minimal complications after extraction. Two had urethral injury, though with no known long term consequences. It was concluded that UroLume Wallstent removal is usually a simple procedure with minimal consequences.

Others have not found stent removal to be so easy. McFarlane et $\mathrm{al}^{45}$ followed 10 patients for at least 5 years post-urethral stenting. Two required stent removal and this was termed difficult, with significant urethral trauma occurring, and five had bladder neck obstruction requiring surgical intervention. ${ }^{45} \mathrm{McFar}-$ lane $e t \mathrm{al}^{46}$ also reported unfavourable long term results of balloon dilatation in 14 patients followed-up for a mean of 55 months. Eighty-five per cent failure rate with long-term follow-up, $68 \%$ occurring in the first year. ${ }^{46}$ McFarlane et al $^{45,46}$ concluded that balloon dilatation 'cannot be recommended for the treatment of DESD'.

Garcia et $a l^{47}$ reported on the use of the Memotherm stent in 24 spinal cord injured men with DSD. Nine had undergone previous sphincterotomy. Follow-up averaged 15 months. All achieved spontaneous reflex voiding with the use of a condom catheter. No per-operative complications occurred. Four out of 24 stents migrated (16\%), and this was managed by insertion of a new stent. Removal was required in two $(8 \%)$ because of infection and stone formation. Six patients had heavy haematuria, though none required transfusion, and one had urinary sepsis. In the 18 with correct stent placement mean LPP decreased from 90 to $35 \mathrm{~cm} \mathrm{H}_{2} \mathrm{O}^{47}$

Sauerwein et $\mathrm{al}^{48}$ used the UroLume Wallstent in 51 patients with SCI and DSD. The patients were followed for between 12-36 months. All those requiring some form of catheterization pre-stenting were rendered catheter free post-stenting. Significant improvements in bladder compliance, detrusor voiding pressure, sphincter passage pressure and autonomic dysreflexia were seen. ${ }^{48}$

Soni $^{49}$ followed 10 patients with DSD who had undergone Memokath stent insertion with 3 to 7 month follow-up. All had PVRs $<50 \mathrm{ml}$ post-stent placement. No stent migration was reported. Minor peri-operative complications included one UTI, and one case of clot retention. ${ }^{49}$

Chartier-Kastler et $a l^{50}$ assessed the efficacy and complications of the Ultraflex urethral stent for the treatment of DSD. Forty consecutive patients with DSD (caused by spinal injury in 30 , MS in six and other neurological diseases in four) who had an Ultraflex stent placed in the membranous urethra were evaluated prospectively, of which five had had previous sphincterotomy. ${ }^{50}$ The mean follow up was 17 months (range $3-51$ months). The mean residual urine decreased from $245 \mathrm{ml}$ before stenting to $65 \mathrm{ml}$ at 12 months followup. Furthermore autonomic dysreflexia decreased or resolved in 12 out of 19 patients. There were no complications during stent placement in this study which required either blood transfusions or rapid stent removal. However, one stent was removed at 13 months for chronic prostatic and urinary tract infection leading to autonomic dysreflexia.

Low et $a l^{51}$ reported a disappointing experience in 24 patients with DSD following Memokath insertion. Nineteen had to have the stent removed either because of persisting urinary tract infection, stent migration or lack of improvement in bladder emptying. They advised against the use of urethral stents in those with chronic urinary tract infection. ${ }^{51}$

Urethral stents seem to be comparable, and in some outcome measures better, than external sphincterotomy, though concerns are still expressed about the long term risk of stent encrustation and there remains a definite risk of stent migration necessitating stent removal or replacement. Depending on the type of stent used this can be accomplished easily or may be associated with considerable urethral trauma. Balloon dilatation also seems to compare well with sphincterotomy, though it is associated with a significant risk of later stricture formation and therefore recurrent bladder outlet obstruction. This presumably relates to the urethral trauma that must inevitably occur at the time of urethral dilatation.

\section{Future developments}

Current treatments for DSD are principally surgical. There are currently no effective drug treatments. Patients are often reluctant to undergo sphincterotomy, partly because of concerns regarding efficacy and complications. Others express reluctance to undergo destruction of their external sphincter, which while functionally abnormal, is anatomically intact. There is a need for an efficacious pharmacological method of treating DSD.

One potential approach to the pharmacological treatment of DSD is augmentation of the physiological actions of the relaxant neurotransmitter at the level of the urethral sphincter, nitric oxide (NO). There is now a considerable amount of experimental data from both animal and human studies to suggest that NO is an important physiological inhibitory neurotransmitter in the urethral sphincter.

Nitric oxide is synthesised by a family of enzymes known as nitric oxide synthases (NOS) that catalyse the conversion of the amino acid L-arginine to NO. NOSstaining neurones have been identified in very high 
density in the urethral sphincters of cats, guinea-pigs, and humans. ${ }^{52-57} \mathrm{NO}$ is thought to play a physiologically important regulatory role in the relaxation of the urethral sphincter probably mediated via cyclic GMP through activation of cyclic GMP-dependent protein kinase $1 .{ }^{58}$ Indeed, in isolated urethral sphincter preparations electrical field stimulated relaxations were abolished by inhibitors of NOS in rats, ${ }^{59}$ pigs $^{60,61}$ and rabbits, ${ }^{62}$ and were enhanced by NO donors. Furthermore, in vivo in both rats and pigs the NOS inhibitors reversibly reduce the magnitude and duration of urethral relaxation during micturition. ${ }^{60,63}$ Similar abolitions of urethral relaxation by NOS inhibitors have been observed in the human urethra. ${ }^{64}$

Further evidence for the role of $\mathrm{NO}$ in the regulation of urethral sphincter relaxation is found in mice with targeted deletion of the gene for neuronal NOS. These mice are found to have hypertrophied dilated bladders and urethral sphincters that do not relax in response to electrical stimulation. ${ }^{65}$

Recently, intraurethral infusion of $\mathrm{NO}$ donors in rats has been shown to reduce urethral pressures. ${ }^{66}$ There have been no reports of the effect of NO donors on sphincter function in humans in vivo.

On the basis of this experimental work we have recently hypothesized that augmentation of external sphincter NO could prove to be an effective pharmacological treatment for DSD in spinal cord injured men. ${ }^{67}$ NO donors, such as glyceryl trinitrate or isosorbide mononitrate could be used to deliver NO to the external sphincter, in much the same way that they are used to relax peripheral vascular smooth muscle in angina. The external sphincter has a rich blood supply and thus NO administered sublingually or orally should reach the urethral sphincter in high concentrations.

A second potential pharmacological target has recently become evident. Ho et al ${ }^{56}$ demonstrated co-localisation of the carbon monoxide (haemoxygenase-2) and NO (neuronal NOS) synthesising enzymes in the nerves innervating the human urethral sphincter. Carbon monoxide has also been shown to relax urethral smooth muscle in both pigs ${ }^{68}$ and rabbits ${ }^{69}$ via activation of cyclic GMP. These studies support a role for carbon monoxide as a relaxant mediator in urethral smooth muscle. Furthermore, this carbon monoxide-mediated relaxant response can be enhanced by increasing the catalytic rate of soluble guanylate cyclase $^{68}$ and hydrogen peroxide. ${ }^{69}$ These findings may have important therapeutic implications.

The prospect of such a pharmacological treatment for DSD is an exciting one and may broaden the therapeutic options available for the management of DSD.

\section{Conclusion}

External sphincterotomy remains the mainstay of treatment for DSD. Numerous studies have shown it frequently results in resolution of hydronephrosis (75-
$90 \%)$, UTI's $(75 \%)$ and autonomic dysreflexia $(>90 \%)$. It also reduces residual urine volumes to $<100 \mathrm{ml}$ in $70-90 \%$ of patients and maximum voiding pressures to $40-50 \mathrm{~cm} \mathrm{H}_{2} \mathrm{O}$ in $80-100 \%$. LPP are reduced to $<40 \mathrm{~cm} \mathrm{H}_{2} \mathrm{O}$ in $35 \%$. However, sphincterotomy is an irreversible procedure, destroying the normal sphincter anatomy and is not without significant complications. These include blood transfusions $(0-13 \%)$, erectile dysfunction $(3-7 \%)$ and urethral stricture $(3-13 \%)$.

Urethral stents and balloon dilatation remain reasonable alternatives. They have the benefit of not destroying the sphincter and in the case of stents, of being potentially reversible. They appear, in the limited data available, to have similar outcomes to sphincterotomy and may be a better alternative in those who have had a previously failed sphincterotomy.

Dorsal rhizotomy combined with sacral anterior nerve root stimulation is an effective option but is a major undertaking and is reserved as a second line treatment.

Botulinum toxin has shown promising initial results in a number of small studies, but data from larger randomised controlled studies is needed.

The prospects for future pharmacological treatments appear promising. The identification of the role of NO and possibly carbon monoxide as urethral smooth muscle relaxants may have important therapeutic implications.

\section{References}

1 Wein AJ. The role of external sphincterotomy for patients with a spinal cord lesion. Editorial comment. $J$ Urol 1998; 160: 961.

2 Frankel HL et al. Long-term survival in spinal cord injury: a fifty year investigation. Spinal Cord 1998; 36: $868-869$

3 Emmett JL. Urinary retention from imbalance of detrusor and vesical neck: treatment by transurethral resection. J Urol 1940; 43: 692-704.

4 Emmett JL et al. Role of the external urethral sphincter in the normal bladder and cord bladder. J Urol 1948; 59: $439-454$.

5 Ross JC, Gibbon NO, Damanski M. Division of the external sphincter in the treatment of the neurogenic bladder. Br J Surg 1967; 54: 627-628.

6 Watkins KH. The bladder function in spinal injury. $\mathrm{Br} J$ Surg 1936; 23: $734-759$.

7 Donovan $\mathrm{H}$. Care of the urinary tract in paraplegic patients. Lancet 1947; 1: 515-518.

8 Ross JC, Damanski M, Gibbon N. Resection of the external urethral sphincter in the paraplegic: preliminary report. J Urol 1958; 79: 742 - 746.

9 Mundy AR. Incisions and exposure. In: Mundy AR (ed). Urodynamic and reconstructive surgery of the lower urinary tract. Edinburgh: Churchill Livingstone, 1996, p 36

10 Catz A et al. The role of external sphincterotomy for patients with spinal cord lesions. Spinal Cord 1997; 35: $48-52$. 
11 Fontaine E et al. Reappraisal of endoscopic sphincterotomy for post-traumatic neurogenic bladder: a prospective study. J Urol 1996; 155: 277 - 280.

12 Carrion HM, Brown BT, Politano VA. External sphincterotomy at the 12 o'clock position. J Urol 1979; 121: $462-463$.

13 Ricottone AR et al. Long-term follow-up of sphincterotomy in the treatment of autonomic dysreflexia. Neurourol Urodyn 1995; 14: $43-46$.

14 Santiago JA. Sphincterotomy failure. J Am Paraplegia Soc 1993; 16: $164-168$.

15 Chancellor MB et al. Sphincteric stent versus external sphincterotomy in spinal cord injured men: prospective randomized multicenter study. J Urol 1999; 161: 1893 1898.

16 McGuire EJ, Woodside JR, Borden TA, Weiss RM. Prognostic value of urodynamic testing in myelodysplastic patients. J Urol 1981; 126: $205-209$.

17 Kim YH, Kattan MW, Boone TB. Bladder leak point pressure: the measure for sphincterotomy success in spinal cord injured patients with external detrusorsphincter dyssynergia. J Urol 1998; 159: 493-496.

18 Perkash I et al. Use of the contact Nd:YAG laser for ablation of the external urethral sphincter. J Urol 1993; 149: $358 \mathrm{~A}$.

19 Rivas A et al. Contact neodymium:yttrium-aluminiumgarnet laser ablation of the external sphincter in spinal cord injured men with detrusor sphincter dyssynergia. Urology 1995; 45: $1028-1031$.

20 Light JK et al. Predictive criteria for failed sphincterotomy in SCI patients. J Urol 1987; 138: $1201-1204$.

21 Lockhart JG, Vorstman B, Winstein D, Politano VA. Sphincterotomy failure in neurogenic bladder disease. $J$ Urol 1986; 135: $86-89$.

22 Nanninga JB, O'Conor VJ, Rosen JS. An explanation for the persistence of residual urine after external sphincterotomy. J Urol 1977; 118: 821 -823.

23 Yang CC, Mayo ME. External urethral sphincterotomy: long-term follow-up. Neurourol Urodyn 1995; 14: 25 - 31 .

24 Juma S, Mostafavi M, Joseph A. Sphincterotomy: longterm complications and warning signs. Neurourol Urodyn 1995; 14: $33-41$.

25 Yalla $\mathrm{S}$ et al. Anteromedian external urethral sphincterotomy: technique, rationale and complications. J Urol 1977; 117: 489 - 493 .

26 Kiviat MD. Transurethral sphincterotomy: relationship of site of incision to postoperative potency and delayed haemorrhage. J Urol 1975; 114: 399-401.

27 Vapnek JM, Couillard DR, Stone AR. Is sphincterotomy the best management of the spinal cord injured bladder? J Urol 1994; 151: 961 - 964.

28 Chancellor MB et al. Prospective comparison of external sphincter balloon dilatation and prosthesis placement with external sphincterotomy in spinal cord injured men. Arch Phys Med Rehabil 1994; 75: 297-305.

29 Schoenfeld L, Carrion HM, Politano VA. Erectile impotence. Complication of external sphincterotomy. Urology 1974; 4: $681-685$.

30 Thomas DG. The effect of trans-urethral surgery on penile erections in spinal cord injury patients. Paraplegia 1976; 13: $286-289$

31 Rossier AB, Ott R. Urinary manometry in spinal cord injury: a follow-up study. Value of cysto-sphincterometrography as an indication for sphincterotomy. $\mathrm{Br} J$ Urol 1974; 46: 439-448.
32 Dollfus $\mathrm{P}$ et al. Impairment of erection after external sphincter resection. Paraplegia 1976; 13: 290.

33 Crane DB, Hackler RH. External sphincterotomy: its effect on erections. J Urol 1976; 116: 316-318.

34 Brindley GS. The first 500 patients with sacral anterior root stimulator implants: general description. Paraplegia 1994; 32: 795.

35 Gibbon NO. A further look at the rationale of 'external sphincterotomy'. Paraplegia 1975; 13: $243-246$.

36 Chancellor MB, Erhard MJ, Rivas DA. Clinical effect of alpha-1 antagonism by terazosin on external and internal urinary sphincter function. J Am Para Soc 1993; 16: 207 214.

37 Perkash I. Efficacy and safety of terazosin to improve voiding in spinal cord injury patients. J Spinal Cord Med 1995; 18: $236-239$.

38 Dykstra DD, Sidi AA. Treatment of detrusor-sphincter dyssynergia with botulinum A toxin: a double-blind study. Arch Phys Med Rehab 1990; 71: 24-26.

39 Schurch B et al. Botulinum-A toxin as a treatment of detrusor-sphincter dyssynergia: A prospective study in 24 spinal cord injury patients. J Urol 1996; 155: 1023 - 1029.

40 Petit $\mathrm{H}$ et al. Botulinum A toxin treatment for detrusorsphincter dyssynergia in spinal cord disease. Spinal Cord 1998; 36: $91-94$.

41 Phelan MW et al. Botulinum toxin urethral sphincter injection to restore bladder emptying in men and women with voiding dysfunction. J Urol 2001; 165: 1107-1110.

42 Gallien $\mathrm{P}$ et al. Treatment of detrusor sphincter dyssynergia by transperineal injection of botulinum toxin. Arch Phys Med Rehab 1998; 79: 715-717.

43 Wheeler Jr JS, Walter JS, Chintam RS, Rao S. Botulinum toxin injections for voiding dysfunction following SCI. $J$ Spinal Cord Med 1998; 21: $227-229$.

44 Gajewski JB et al. Removal of UroLume endoprosthesis: experience of the North American Study Group for detrusor-sphincter dyssynergia application. J Urol 2000; 163: $773-776$.

45 McFarlane JP, Foley SJ, Shah PJR. Long-term outcome of permanent urethral stents in the treatment of detrusorsphincter dyssynergia. Br J Urol 1996; 78: $729-732$.

46 McFarlane JP, Foley SJ, Shah PJR. Balloon dilatation of the external urethral sphincter in the treatment of detrusor-sphincter dyssynergia. Spinal Cord 1997; 35: $96-98$.

47 Garcia J, Salvador S, Montoto A. Intraurethral stent prosthesis in spinal cord injured patients with sphincter dyssynergia. Spinal Cord 1999; 37: 54-57.

48 Sauerwein D, Gross AJ, Kutzenberger J, Ringert RH. Wallstents in patients with detrusor-sphincter dyssynergia. J Urol 1995; 154: 495-497.

49 Soni BM. Memokath. Paraplegia 1994; 32: 480-488.

50 Chartier-Kastler E et al. A urethral stent for the treatment of detrusor striated sphincter dyssynergia. $\mathrm{Br}$ J Urol (Int) 2000; 86: 52-57.

51 Low AI, McRae PJ. Use of the Memokath for detrusorsphincter dyssynergia after spinal cord injury: a cautionary tale. Spinal Cord 1998; 36: 39 - 44.

52 Keast JR, Kawatani M. Extensive distribution of NADPH diaphorase activity in the nerve supply of the cat lower urinary tract. Autonom Nerv Syst 1994; 50: $116-169$ 
53 Smet PJ, Jonavicius J, Marshall VR, de Vente J. Distribution of nitric oxide synthase immunoreactive nerves and identification of the cellular targets of nitric oxide in guinea-pig and human urinary bladder by cGMP immunohistochemistry. Neuroscience 1996; 71: 337-348.

54 Pinna C, Eberini I, Puglisi L, Burnstock G. Presence of constitutive endothelial nitric oxide synthase immunoreactivity in urothelial cells of hamster proximal urethra. Eur J Pharmacol 1999; 367: 85-89.

55 Ho KM et al. Nitric oxide synthase in the heterogeneous population of intramural striated muscle fibres of the human membranous urethral sphincter. J Urol 1998; 159: $1091-1096$

56 Ho KM et al. Co-localisation of carbon monoxide and nitric oxide synthesizing enzymes in the human urethral sphincter. J Urol 1999; 161: $1968-1972$.

57 Garcia-Pascual A et al. Characterisation of nitric oxide synthase activity in sheep urinary tract: functional implications. Br J Pharmacol 1996; 118: 905-914.

58 Persson $\mathrm{K}$ et al. Functional characteristics or urinary tract smooth muscles in mice lacking cGMP protein kinase type 1. Am J Physiol Regul Integr Comp Physiol 2000; 279: R1112-R1120.

59 Parlani M, Conte B, Manzini S. Nonadrenergic, noncholinergic inhibitory control of the rat external urethral sphincter: involvement of nitric oxide. J Pharmacol Exp Ther 1993; 265: $713-719$.

60 Bridgewater M, Macneil HF, Brading AF. Regulation of tone in pig urethral smooth muscle. J Urol 1993; 150: $223-228$

61 Werkstrom $\mathrm{V}$ et al. Factors involved in the relaxation of female pig urethra evoked by electrical field stimulation. Br J Pharmacol 1995; 116: 1599-1604.
62 Lee JG, Wein AJ, Levin RM. Comparative pharmacology of the male and female rabbit bladder neck and urethra: involvement of nitric oxide. Pharmacology 1994; 48: $250-259$.

63 Bennett BC et al. Neural control of urethral outlet activity in vivo: role of nitric oxide. J Urol 1995; 153: $2004-2009$.

64 Ehren I et al. Localisation of nitric oxide synthase activity in the human lower urinary tract and its correlation with neuroeffector responses. Urology 1994; 44: $683-687$.

65 Burnett AL et al. Urinary bladder-urethral sphincter dysfunction in mice with targeted disruption of neuronal nitric oxide synthase models idiopathic voiding disorders in humans. Nat Med 1997; 3: $571-574$.

66 Fraser MO et al. Intraurethral nitric oxide dono relaxes the urethral smooth muscle. J Urol 1998; 159: 23A.

67 Mamas M, Reynard JM, Brading AF. Augmentation of nitric oxide to treat detrusor-external sphincter dyssynergia in spinal cord injury. Lancet 2001; 357: $1964-$ 1970 .

68 Schroder A, Hedlund P, Andersson KE. Carbon monoxide relaxes the female pig urethra as effectively as nitric oxide in the presence of YC-1. J Urol 2002; 167: $250-259$

69 Naseem KM et al. Relaxation of rabbit lower urinary tract smooth muscle by nitric oxide and carbon monoxide: modulation by hydrogen peroxide. Eur $J$ Phamacol 2000; 387: 329-335. 